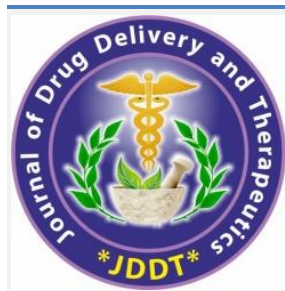

Open Access Full Text Article
Available online on 15.01.2021 at http://jddtonline.info

\section{Journal of Drug Delivery and Therapeutics}

Open Access to Pharmaceutical and Medical Research

(C) 2011-21, publisher and licensee JDDT, This is an Open Access article which permits unrestricted non-commercial use(CC By-NC), provided the original work is properly cited

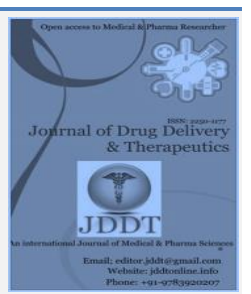

Review Article

\title{
Microsponge as an Emerging Technique in Novel Drug Delivery System
}

\author{
Borawake Payal D*1, Kauslya Arumugam ${ }^{1}$, Shinde Jitendra V 2, Chavan Rajashree S 3 \\ 1 Department of Pharmaceutics, Pune District Education Association's, Seth Govind Raghunath Sable College of Pharmacy, Saswad, Pune, \\ Maharashtra, India
}

${ }^{2}$ HOD, Department of Pharmaceutics, Pune District Education Association's, Seth Govind Raghunath Sable College of Pharmacy, Sas wad, Pune, Maharashtra, India

${ }^{3}$ Principal, Pune District Education Association's, Seth Govind Raghunath Sable College of Pharmacy, Saswad, Pune, Maharashtra, India

\section{Article Info:}

Article History:

Received 06 Oct 2020;

Review Completed 19 Dec 2020

Accepted 27 Dec 2020;

Available online 15 Jan 2021

\section{Cite this article as:}

Borawake PD, Kauslya A, Shinde JV, Chavan RS,

Microsponge as an Emerging Technique in Novel Drug

Delivery System, Journal of Drug Delivery and

Therapeutics. 2021; 11(1):171-181

DOI: http://dx.doi.org/10.22270/jddt.v11i1.4492

*Address for Correspondence:

Borawake Payal D, Department of Pharmaceutics, Pune

District Education Association's, Seth Govind

Raghunath Sable College of Pharmacy, Saswad, Pune,

Maharashtra, India

\section{Abstract}

Numbers of developments are implemented in drug delivery system to achieve the goals of optimized efficacy, cost effectiveness of therapy. One of the latest, novel and highly evolving technologies is microsponge drug delivery system which gives controlled release and site specific delivery of active ingredients. They are highly cross linked, porous and polymeric microspheres with size range of $5-300 \mu \mathrm{m}$. This system is emerging as valuable option for topical delivery of drugs due to characteristics like decreased side effects, improved stability, better formulation flexibility, superior product performance. It is having number of applications in oral, topical, ocular and biopharmaceuticals delivery. The current review describes microsponge technology and details of the formulation methods, evaluation, programmable release mechanisms and applications.

Keywords: Microsponges; Controlled release; Quasi emulsion solvent diffusion; Programmable drug release; Oral administration; Topical drug delivery.

\section{INTRODUCTION:}

Microsponges are highly cross linked, porous and polymeric microspheres entrapping broad range of active pharmaceutical ingredients and formulations like powders, lotions, creams and tablets can be prepared for drug delivery. Microsponges possess consistent voids of the particles whose size ranges from $5 \mu \mathrm{m}$ to $300 \mu \mathrm{m}$ which depends on the degree of smoothness which is required at the end of the formulation. It is one of the novel and modern approach for sustained drug delivery. 1 Delivering drug at predetermined rate and to a specific site in human body is difficult and is one of the challenge that is faced by the pharmaceutical industries when considering conventional dosage forms, so to overcome this challenge, various NDDS were developed. Microsponges are one of them, which was discovered by Richard won in 1987 and original patents were designated to Advanced polymer system, Inc. This company developed many variations in this technology and this then applied not only to cosmetic but also OTC and prescription pharmaceutical products. ${ }^{2}$
Typically, $25 \mu \mathrm{m}$ particle have approximately $2,50,000$ pores with internal pore structure equals to length of about $10 \mathrm{ft}$ that provides $1 \mathrm{ml} / \mathrm{g}$ pore volume for massive drug retention. The surface may varied from $20-500 \mathrm{~m}^{2} / \mathrm{g}$. Pore volume can also varied from $0.1-0.3 \mathrm{~cm}^{3} / \mathrm{g}$. The feature provides large reservoir type system in each of the microsponge, which is then loaded with capable weight of drug. ${ }^{3}$ As the size of pore diameter is small, it is unable to bacteria whose size range is 0.007-0.2 $\mu \mathrm{m}$ to penetrate through pore structure of microsponge, leaving the beads sterile after manufacturing and thus do not require addition of preservatives during formulation. So, it represents safety concern of microsponges regarding bacterial contamination of material entrapped. Since microsponges is reservoir type system, it Potentially delivers large number of substances like fragrance, emollients, sunscreens, anti-microbials, antifungals, anti-acne as well as anti-inflammatory agents in controlled manner. 4 The structure of microsponges is shown in figure 1. 


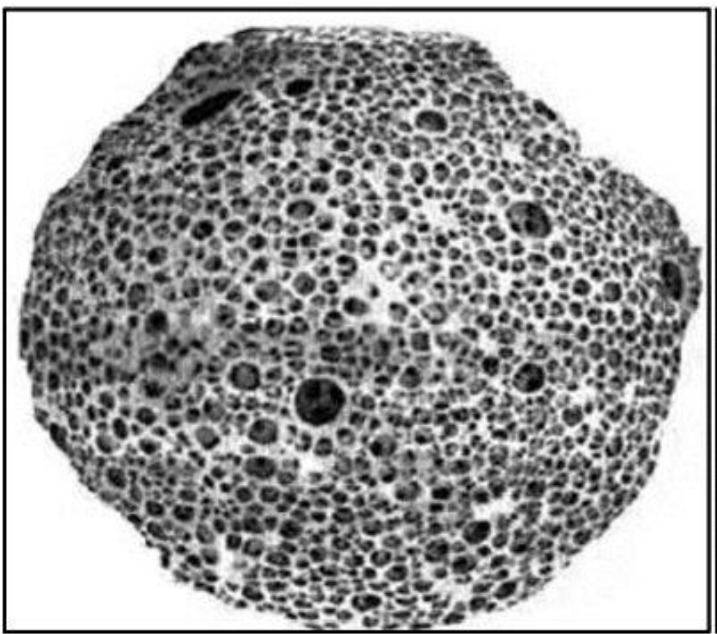

(A)

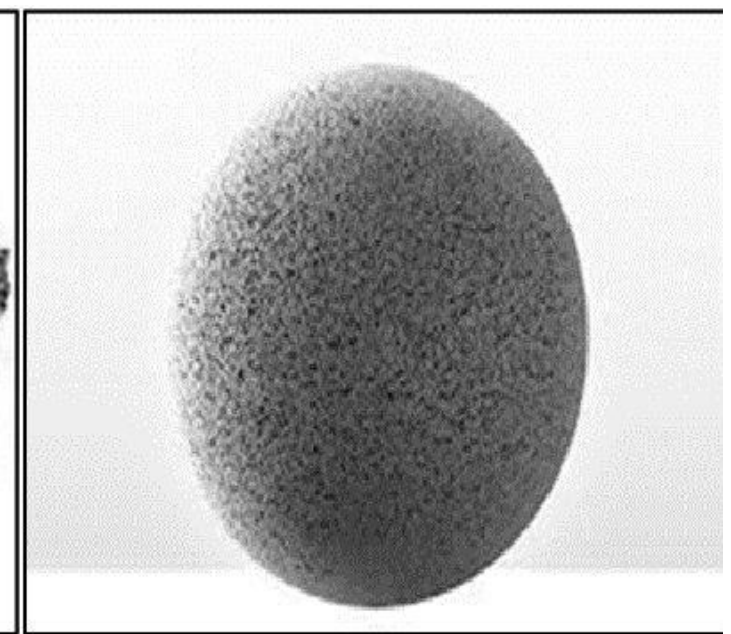

(B)

Figure 1: (A) Highly porous structure of microsponges (B )Microsponges 31

\section{NEED OF MICROSPONGES IN TOPICAL DRUG DELIVERY:}

Topical agents are administered on skin that acts on outer layers of skin. Though there is improved efficacy of certain drugs through topical route, but it encompasses problems like lack of patient compliance due to greasy, sticky feel in case of ointments, irritation and allergic reactions in some individuals, uncontrolled evaporation of drug, objectionable odour and drug vehicle incompatibility issues. Also there is lack of efficient vehicles for controlled and localized drug delivery in stratum corneum and underlying layers. Due to low efficiency of topical delivery system, high concentration of active ingredient needs to be added in vehicle. When formulation is applied, there is rapid release of drug which leads to rapid absorption of drug in skin that causes excessive accumulation of active ingredients which in turn produces irritation and allergy of skin. So there is need to increase amount of drug either on skin surface or within epidermis and reduce transdermal penetration. In such cases, Microsponge drug delivery system is used for effective drug delivery with significant reduction in irritation effects of some drugs without reducing their efficacy. As microsponges are tiny, inert and non-destructible spheres, instead of passing through skin layers they get trapped in small holes and crannies of skin and releases the therapeutic agent by diffusion in controlled manner as per need of skin, thus preventing unnecessary accumulation of therapeutic agents in skin layers. 5,6

\section{DIFFERENTIATION BETWEEN MICROCAPSULE AND MICROSPONGE:}

Microcapsule is encapsulated, complete shell like structure. Once the shell is ruptured, active ingredients within capsular structure get released. In this case, $100 \%$ drug is released so this system doesn't have control on release rate. But, microsponges possess porous, spongy structure. Release of drug can be controlled by altering conditions like temperature, $\mathrm{pH}$, pressure, solubility, partition coefficient. Thus the goal of programmable, controlled and sustained drug delivery is achieved through microsponge system. ${ }^{7}$

\section{DIFFERENTIATION BETWEEN LIPOSOMES AND MICROSPONGES:}

Liposome is spherical vesicle having phospholipid bilayer that can transport aqueous as well as lipid drugs but possess problem of low entrapment efficiency which is only about
$30 \%$ as compared to microsponges whose entrapment efficiency is about $50-60 \%$. Liposomes are chemically unstable, but microsponges are fully stable over wide $\mathrm{pH}$ range, temperature. When considered stability against microbial contamination, preservation needed in liposome formulation but microsponges doesn't require it due to pore structure. Only Chemical composition and particle size can be programmable in liposomes while more characters like resiliency, pore volume, pore diameter can be controlled along with chemical composition and particle size in microsponges. Liposomes require ultra pure raw material making this system expensive however raw materials of adequate purity are easily available for microsponges making the system cost effective. ${ }^{8}$

\section{DRUG REQUIREMENTS TO BE ENTRAPPED IN MICROSPONGES:}

There are some requirements of the active pharmaceutical agents that need to be fulfilled for effective entrapment into microsponges. They are as follows:

1) It should get completely soluble in monomer or get soluble by adding very little amount of water immiscible solvent.

2) It must be insoluble in water.

3) It must show an inertness for monomers.

4) It should have stability with polymerization catalyst as well as with polymerization conditions. ${ }^{9}$

5) The viscosity of the mixture should not get increased during formulation.

6) It must have limited solubility in vehicle for avoiding cosmetic issues.

7) Only $10-12 \% \mathrm{w} / \mathrm{w}$ of microsponges should include into vehicle. If this concentration not achieved, vehicle will diminishes microsponges before its application.

8) Design of polymer and payload of drug must be optimized to get desired release rate for a specified time period..$^{10}$

9) Spherical structure of microsponges must be preserved.

10) Molecular weight of Active pharmaceutical ingredient should be less i.e. $600 \mathrm{~g} / \mathrm{mole}$ so that it can penetrate easily.

11) Half life $\left(t_{1 / 2}\right)$ of API should be less than 5 hrs to provide sustained action. ${ }^{11}$ 


\section{SALIENT FEATURES OF MICROSPONGE DELIVERY SYSTEM (MDS):}

1) Stable over pH 1 to 11.

2) Thermally very stable i.e. up to $130^{\circ} \mathrm{c}$.

3) Self-sterilizing due to average pore diameter of $0.25 \mu \mathrm{m}$ through which microbes cannot penetrate. Thus, formulation does not require addition of preservatives.

4) Shows compatibility with most of the vehicles and additives.

5) High payload capacity (50-60\% by weight), though remain in form of superfine, free flowing powder.

6) Cost effective as compared to other drug delivery systems.

7) Superior oil control.12

\section{ADVANTAGES OF MICROSPONGES TECHNOLOGY:}

$>$ Improved product elegance.

$>$ Reduced skin irritation thus producing better patient compliance.

$>$ Improved bioavailability of active pharmaceutical ingredients.

$>$ Enhanced product performance.

$>$ Provide extended release of medicament and gives continuous action up to $12 \mathrm{hrs}$.

$>$ High surface area so higher entrapment efficiency.

$>$ Microsponges are non-allergenic, non-irritating, non mutagenic and non-toxic.

$>$ Improved physical, chemical and thermal stability.

$>$ Better formulation flexibility.

$>$ Improved efficacy, safety in treatment.

$>$ Novel product forms can be developed flexibly.

D Drug can be directly applied to target organs.

> Capability of absorbing oily skin secretions thereby giving shiny look to the skin.

$>$ Enhanced material processing.

> Immiscible products can be incorporated easily.13,14

\section{LIMITATIONS OF MDS:}

- Method by which microsponges are formulated uses organic solvents that have environmental hazard.

- Some solvents are highly inflammable that possess a safety hazard.

- Toxicity and health hazards observed in cases where traces of residual monomers remained. 15

\section{VARIOUS DRUGS USED IN MICROSPONGE TECHNOLOGY:16,17}

* Ketoprofen (NSAID)

* Benzoyl peroxide (Anti-acne)

* Fluconazole (Anti-fungal)

* Ibuprofen (NSAID)
* Tretinoin (Vitamin-A)

* Trolamine (Analgesic)

+ Paracetamol (NSAID)

* Tioconazole (Anti-fungal)

* Acyclovir sodium (Anti-viral)

* Miconazole (Anti-fungal)

* Fluocinolone acetonide (Corticosteroid)

* Prednisolone (Corticosteroid)

* Erythromycin (Anti-biotic)

* Mupirocin (Anti-bacterial)

* Indomethacin (NSAID)

* Lornoxicam (NSAID)

* Curcumin (Anti-inflammatory)

* Febuxostat (Anti-gout)

* Flurbiprofen (NSAID)

POLYMERS FOR FORMULATION OF MDS: 18

Eudragit RS 100

Eudragit RL 100

Ethyl cellulose

Cellulose acetate

Polyvinyl acetate

Carbopol 934

Carbopol 940

Polymethacrylates

Polystyrene

Eudrajit EPO

\section{PREVIOUS RESEARCH WORK DONE ON MICROSPONGES:}

- Taghi et al., prepared microsponges (MS) of Dutasteride (DU) for enhancing solubility as dutasteride is BCS classII drug with low water solubility, less oral absorption and is used to treat benign prostate hyperplasia. Quasi emulsion method was used for preparing microsponges by using Eudragit S100 as polymer, glycerol as plasticizer and PVA as stabilizer. Variable factors like D:P ratio, different concentrations of PVA, Stirring rate were employed and formulations optimized for production yield, EE, particle size, in vitro drug release. Saturation solubility study confirmed enhanced solubility of DU MS as compared to pure DU. $28 \%$ and $42 \%$ solubility enhancement was observed in distilled water and $0.1 \mathrm{~N}$ $\mathrm{HCl}$, respectively of MS. Thus, the present study showed that when microsponges of dutasteride were prepared, there was increase in aqueous solubility and faster dissolution rate as compared to pure drug. ${ }^{19}$

- Kshirsagar et al., developed microsponges for sustained action of flurbiprofen. Flurbiprofen is NSAID that belongs to phenylalkanoic acid derivative class which acts as inhibitor of prostaglandin synthesis. For Preparation of flurbiprofen microsponges, emulsion solvent diffusion technique was employed with internal phase, containing ethyl cellulose, Eudrajit RS 100, Triethyl citrate. PVA in water was used as an external phase. There were no any 
drug-polymer interaction observed as per DSC and FTIR. The gel loaded with microsponges then studied for In vitro and Ex vivo drug release. Formulation showed better retention of drug in skin as compared to marketed flurbiprofen gel (BRUGEL). ${ }^{20}$

- Elfaham et al., prepared acetazolamide microsponges. For ophthalmic drug delivery, microsponges are then incorporated into in-situ gel. Acetazolamide is an effective drug for treating glaucoma. The Quasi emulsion technique was used for preparing stable microsponges and incorporated them into 25\% PF-127 in situ gel. Various proportions of polymer (ethyl cellulose) with drug were tried and 2:1 proportion was best selected whose \% EE was near about $82 \%$, PDI of 0.22 that fits for ophthalmic administration. Later, formulated gel was characterized for physical and chemical properties and in vivo studies showed non irritancy to rabbit's eye. Thus, formulation was efficiently used for topical ophthalmic delivery. ${ }^{21}$

- Othman et al., used 0/0 emulsion solvent diffusion technique for preparing sustained release microsponges of 5-Florouracil incorporated into Eudragit RS 100 for treating colon cancer. They investigated effect of drug as to polymer ratio, $\mathrm{Mg}$ Stearate as to solvent ratio and solvent as to polymer ratio on particle size, entrapment efficiency, in vitro drug release profiles. Study showed that by increasing D:P ratio, entrapment efficiency also increased. As polymer concentration increased, particle size also increases. Finally, it was concluded that 5FUmicrosponge system can be substituted with 5-FU oral anticancer treatment. ${ }^{22}$

- Desavathu et al., developed microsponges of valsartan for enhancing its therapeutic effects, minimizing side effects thereby improving disease condition. Valsartan is an anti-hypertensive drug; its microsponges were prepared by quasi emulsion technique via applying various stirring rates. By FT-IR spectroscopy, drug excipient interactions were studied. Drug: polymer ratio, stirring rates influences particle size as well as drug release pattern. The observation was, as $\mathrm{D}: \mathrm{P}$ ratio increased, particle size gets decreased and production yield get increased. Also, when high stirring rate was applied, production yield was increased and particle size get decreased.23

- Charagonda et al., formulated famotidine floating microsponges. Famotidine is $\mathrm{H} 2$ receptor antagonist used to treat various ulcers like gastric ulcer, duodenal ulcer, stress ulcers, gastritis. For preparation, modified quasi emulsion technique was employed. Various concentrations of Eudragit S100 and PVA were tried and formulations were characterized for parameters like \% $\mathrm{EE}, \%$ buoyancy and percentage cumulative drug release. Drug: polymer concentrations tried was 1:4, 1:8, 1:12, 1:16. There were no drug excipients interactions observed and confirmed by FT-IR analysis. SEM images showed porous structure of microsponges. This research presented new approach for treating ulcer based on floatability of microsponges. ${ }^{24}$

- Pawar et al., formulated microsponge gel of oxybenzone for topical drug delivery. Oxybenzone is sunscreen agent having broad spectrum of activity. Quasi emulsion technique was employed for oxybenzone loaded ethyl cellulose microsponges and then is optimized by $3^{2}$ factorial designs. The suitable formulation then incorporated in HPMC base to obtain gel. In vitro as well as ex vivo study showed better topical drug retention with improved SPF as compared to marketed formulation. 25

- Bhimavarapu et al., prepared itraconazole loaded microsponges by employing quasi emulsion method. Two different ratios of drug and polymer were selected i.e. 1:6 and 1:12. Prepared formulations then evaluated for morphology, surface anatomy, loading efficiency, percentage yield, drug excipient interactions, in vitro drug release kinetics. At last authors concluded that formulation with ratio 1:6 was most reliable to provide extended drug release pattern. ${ }^{26}$

\section{METHOD OF PREPARATION:}

According to physico-chemical properties of drug, the process of loading of drug in microsponges are:

1) One-step process

2) Two-step process.

One Step Process: An inert, non-polar drug is loaded through this process. This type of drugs creates porogen i.e. porous structure. Polymerization process neither affects nor activates the porogen drug. Porogen is stable to free radicals.

Two Step Process: This process is employed when drug is susceptible to polymerization environment. In this method, substitute porogen is used during polymerization and is replaced with active substance under mild experimental environment. ${ }^{27}$

Following are some preparation methods of microsponges.

1) Liquid-liquid Suspension polymerization method

2) Quasi emulsion solvent diffusion technique

3) Water in oil in water emulsion solvent technique

4) Addition of porogen method

5) Oil in oil emulsion solvent diffusion technique

6) Lyophilization method

7) Vibrating orifice aerosol generator method

8) Ultrasound assisted method

9) Electro hydrodynamic atomization method

\section{1) Liquid-liquid suspension polymerization method:}

In this, porous microspheres are formulated in liquid-liquid system. It is one step process and bottom-up approach that starts with monomer. Firstly, suitable solvent is taken and in that monomers as well as active ingredients are dissolved. This solution then with agitation dispersed within external phase that contains surfactants and suspending agents. When preferred sized distinct droplets are observed, by adding catalyst or by irradiation or by change in temperature, polymerization is initiated. After completion of polymerization process, liquid is removed. Reaction vessel for the method is shown in figure 2 .

Reservoir type of system is developed through this method, which opens at the outside via pores. In some cases, throughout the polymerization, an inert liquid which is not miscible with water but fully miscible with monomer is utilized for forming porous system. When polymerization is completed, solvent is removed that leaves microsponges behind that can be incorporated with number of active substances and can act as topical carriers. Whereas in few cases, solvent is used for efficient and faster incorporation of actives. 


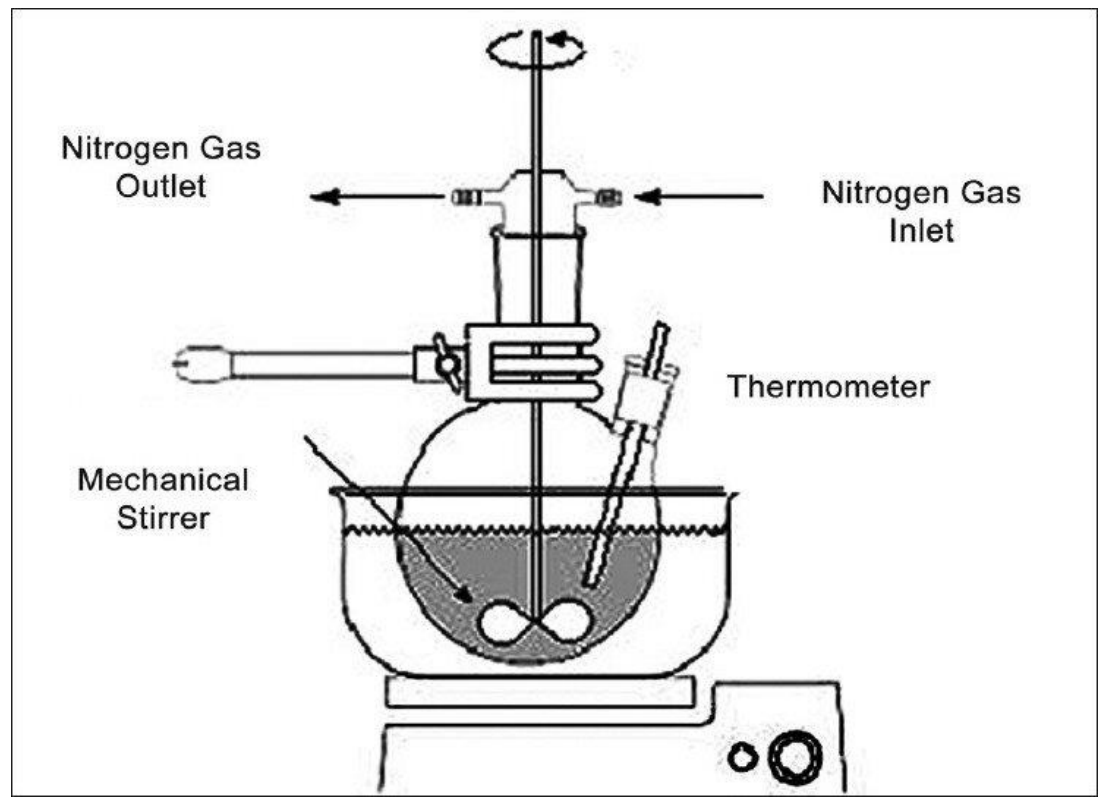

Figure 2: Microsponge preparation by liquid-liquid suspension polymerization 29

Steps involved in suspension polymerization method can be described as follows :

- Selection of single or multiple monomers.

- Chain monomer development as polymerization initiates.

- Ladder formation due to cross linking among chain monomers.

- Formation of spherical particles (microspheres).

- Formation of bunches as a result of agglomeration of spherical particles.

- Microsphere bunches binding for formation of microsponges. 28,29

\section{2) Quasi emulsion solvent diffusion method:}

It is two step method in which different amounts of polymers are used. It is top to down approach which starts by using preformed polymer. The method produces matrix type of porous microsponges. It involves development of quasi emulsion of two totally different phases. The two phases are inner phase and external phase. Inner phase consists of active therapeutic agent, polymer, volatile solvent and plasticizer. Plasticizer used is Triethyl citrate that aids the plasticity and is added at an amount of $20 \%$ of polymer. External phase consist of polyvinyl alcohol in distilled water as shown in figure 3.
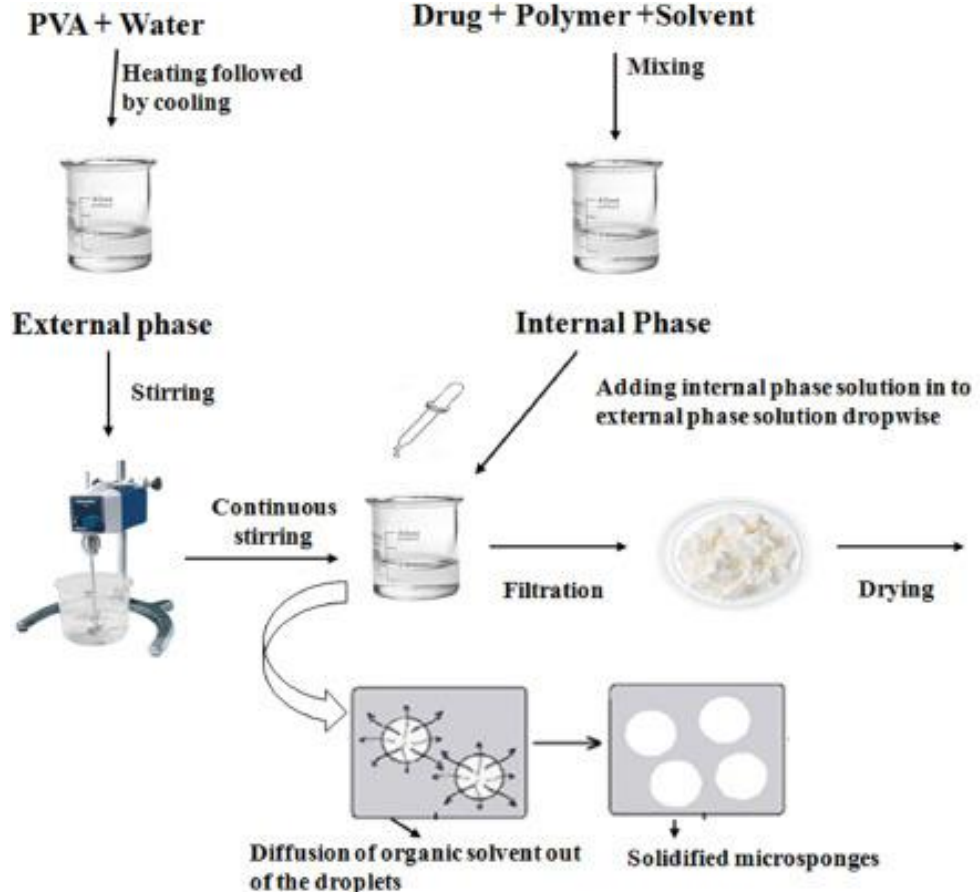

\section{Drug + Polymer + Solvent}

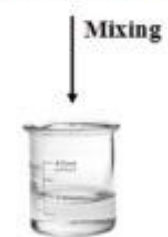

Internal Phase

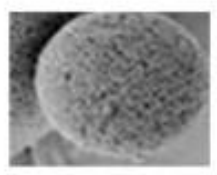

Micro sponges

Figure 3: Quasi emulsion solvent diffusion method 66 
Steps involved in preparation can be described as:

- Preparation of internal phase by dissolving polymer in volatile solvent like ethyl alcohol, acetone or dichloromethane.

- Slow addition of drug to above solution and ultrasonication at $35^{\circ} \mathrm{c}$ for dissolving of drug.

- Inner phase pouring in an outer phase with vigorous stirring for 60 minutes.

- Vigorous stirring results in development of distinct globules which are called as quasi emulsion globules.

- Extraction of solvent from globules to form insoluble, rigid microsponges.

- Separation of microsponges by filtering the mixture.

- Washing and drying of microsponges in an oven at $40^{\circ} \mathrm{C}$ upto $12 \mathrm{hrs}$.

- Weighing to determine Percentage yield. ${ }^{30,31}$

3) Water in oil in water $(w / o / w)$ emulsion solvent diffusion method:

It is new method for preparing biodegradable, microspheres in which inner aqueous phase contains an emulsifier is dispersed in organic polymeric phase. It will prepare w/o emulsion. Then, this emulsion is dispersed in external aqueous phase consisting of polyvinyl alcohol solution that forms double emulsion. Hydrophilic as well as hydrophobic drugs are entrapped through this method. Also thermolabile drugs like proteins can be entrapped. ${ }^{32}$

\section{4) Addition of porogen:}

It is modified $\mathrm{w} / \mathrm{o} / \mathrm{w}$ double emulsion evaporation method in which porogen is used instead of internal aqueous phase (w/o). Hydrogen peroxide or sodium bicarbonate can be used as porogen which is gas-liberating agent which will get decomposed into water and oxygen under influence of catalyst and oxygen bubbles will creates internal pores within microsponges.

Polymer was dissolved in an organic solvent and then porogen was dispersed within that polymeric solution which creates w/o emulsion which is then homogenized and transferred into Aqueous PVA phase and re-emulsified using overhead propeller for $4 \mathrm{hrs}$. Then, Catalyst is added and organic solvent will evaporate leaving behind microsponges that were washed and lyophilized in freeze dryer. ${ }^{33}$

\section{5) Oil in oil (0/0) emulsion solvent diffusion method:}

Within this method, specified amount of polymer was dissolved in dispersing solvent like acetone or dichloromethane. After formation of clear solution, deflocculating agent like Mg Stearate was added and then mixture was ultrasonicated for obtaining homogenous dispersion. The mixture then added into continuous oil phase like liquid paraffin with continuous stirring for 45 min. Then emulsion was heated to $35^{\circ} \mathrm{c}$ and stirred for 30 min. At this stage, solvent was removed by diffusion and evaporated. Finally, solidified microsponges were filtered, washed, air dried and stored in dessicator. Sometimes, pore inducers like sucrose, pre-gelatinized starch were added. 34

\section{6) Lyophilization technique:}

Gelation method prepares microspheres. This microsphere can be converted into porous microsponges by using lyophilization technique. In this, microspheres were incubated and lyophilized. For incubation, the solution of chitosan hydrochloride was used. During lyophilization, removal of solvent takes place which give rise to formation of porous microsponges.

Advantages: Quick and rapid process.

Disadvantages: Production of cracked, shrunken particles as a result of rapid removal of solvent. 35

\section{7) Vibrating orifice aerosol generator technique:}

This method was initially reported for the formulation of lipid bilayered mesoporous silica particles. Polymeric solution was prepared by dissolving polymers in an organic solvent and in that drug was added. Then polymeric solution was loaded into syringe of VOAG apparatus with appropriate flow rate. Constant stream of monodispers droplets was generated due to vibrating frequencies. Droplets then collected into aqueous solution of PVA and dispersion was stirred for $24 \mathrm{hrs}$ for solvent evaporation. Lastly, through filtration, washing, centrifuging and by drying, solidified micro particles were obtained. 36

\section{8) Ultrasound assisted method:}

This method is modification of liquid-liquid suspension polymerization. For formulating microsponges, monomer and cross linking agents are used. Beta-cyclodextrin used as monomer and diphenyl carbonate as cross linker. After heating and sonication, resultant mixture was kept to cool. The obtained product was then crushed to obtain porous, irregular microparticles.

Advantages: No traces of solvent, quick reproducible results obtain.

Disadvantages: Toxic residues of cross linking agent get entrapped, Irregular structure may obtained. ${ }^{37}$

\section{9) Electro hydrodynamic atomization method:}

This method was used for preparation of porous microspheres of chitosan. For generation of bubbles, solution of chitosan was kept for sonication. Then, that suspension was taken in the syringe, perfused via capillary and subjected to electro hydrodynamic atomization. Ion induced gelation was used for preparing microparticles. Appropriate flow rate and voltage was applied through setup. Aqueous $\mathrm{NaOH}$ solution was prepared and kept in beaker. Beaker placed on magnetic stirrer and was continuously stirred during electrospraying of chitosan solution it results in gelation of electrosprayed chitosan. The chitosan droplets collected in $\mathrm{NaOH}$ solution will attain spherical shape after a hour. ${ }^{38}$

\section{DRUG RELEASE MECHANISM FROM MICROSPONGES:}

\section{A) Programmable drug release mechanism:}

Through one or more external stimuli or trigger, the active ingredient entrapped in microsponges can be released over the time.

\section{1) Temperature triggered release:}

In this mechanism, due to temperature change, active ingredient released through the system. Some drugs are often too viscous at room temperature so they cannot flow impulsively from porous system. But when applied to skin, increase in temperature of skin leads to increased flow rate and thus continuous release of drug.

2) Pressure triggered release: 
In this mechanism, when pressure is applied or when dosage form rubbed onto the skin, entrapped drug get released through microsponges. Amount of drug released depends on various characteristics of microsponges like resiliency, various process variables, type of material used. 39

\section{3) Solubility triggered release:}

Porous systems incorporated with water soluble excipient releases drug in presence of water. Sometimes release is driven by diffusion mechanism by considering partition coefficient between drug and external system.

\section{4) pH triggered release:}

In this mechanism, change in $\mathrm{pH}$ triggers drug release and is achieved by modification of coating on microsponges for $\mathrm{pH}$ based actives. 40

\section{B) Hypothetical drug release mechanism:}

Drug is added in vehicle in an entrapped form. Due to open structure, drug can freely go in and out of microsponge system as well as in vehicle till equilibrium is achieved. That causes saturation of vehicle with drug. When formulation is applied to the skin, drug within the vehicle can get absorbed in the skin that results in unsaturation of vehicle and thus equilibrium is depleted. To restore this equilibrium, drug will again moves from microsponge into the vehicle, and from vehicle into the skin till drying or absorbing of vehicle occurs.

Then, microsponge particles retained on stratum corneum surface will gradually releases the active drug over prolonged time. Vehicles are of much importance during microsponges formulation as they have role in gradual, continuous release of active from the formulation. So during selection, it should be considered that selected vehicle has minimal solubilising power for active ingredient. To avoid premature leaching of drug from polymer, dosage form can be formulated with some free and some entrapped drug moieties. ${ }^{41,42}$

\section{Factors affecting drug release from microsponges:}

- Physicochemical characteristics of entrapped API.

- Physical parameters of microsponges such as pore diameter, volume.

- Properties of vehicle that is used for dispersing microsponges .

- Factors like pore characteristics, monomer composition. ${ }^{43}$

\section{EVALUATION OF MICROSPONGES:}

Particle size \& size distribution: Particle size and its distribution evaluation is very crucial parameter as size of particle affects texture, stability of formulation and is determined by using either light microscope or electron microscope. Particle size of loaded as well as unloaded microsponges is determined by using laser light diffractometry. ${ }^{44}$

Morphological analysis: Surface morphology of microsponges is analyzed by Scanning Electron Microscope. Microsponges are covered with gold palladium in an argon environment at room temperature by ion sputtering method using auto fine coater. Then microsponges placed on sample holder and scanning electron micrographs are taken. 45

Production yield and drug content: Production yield can be obtained by dividing practical weight of microsponges with theoretical weight i.e. total amount of drug and polymer used.

For drug content determination, specific weight of microsponges is dissolved in an appropriate solvent to disrupt microparticles and is ultrasonicated. Dispersion is filtered; absorbance is measured at wavelength of specified wavelength of drug using UV-VIS spectrophotometer. 46

$$
\begin{gathered}
\text { Production yield }(\%)=\frac{\text { Practical weight of microsponges }}{\text { Theoretical weight of microsponges }} \times 100 \\
\text { Drug content }(\%)=\frac{\text { Practical drug content in microsponges }}{\text { Theoretical weight of microsponges }} \times 100
\end{gathered}
$$

True density determination: It is measured by using an ultra-pycnometer in an atmosphere of helium gas and mean of density readings is taken.

Entrapment efficiency determination: Entrapment efficiency is calculated y using following equation. ${ }^{47}$

Entrapment Efficiency (\%)

$$
=\frac{\text { Amount of drug entrapped in microsponge }}{\text { Total amount of drug used }} \times 100
$$

Dissolution study: In-vitro dissolution data of microsponges is obtained by using USP XXIII modified basket dissolution apparatus which consists of $5 \mathrm{~m}$ stainless steel mesh. The speed of rotation is maintained at $150 \mathrm{rpm}$. Samples at various intervals are pipetted and analyzed using suitable analytical method. To study the permeation profile and drug release from MS, various apparatus, media are used that are given in table 1 . Dissolution medium selected according to solubilty of active ingredient for maintaining proper sink conditions. ${ }^{48}$

Table 1: Various apparatus and media used in dissolution study

\begin{tabular}{|l|l|l|}
\hline Apparatus & Medium used & Dosage form \\
\hline USP apparatus I & $\begin{array}{l}\text { Simulated fluid } \\
\text { Phosphate buffer 7.4 }\end{array}$ & $\begin{array}{l}\text { Tablet } \\
\text { Hydrogel }\end{array}$ \\
\hline USP apparatus II & $0.1 \mathrm{~N} \mathrm{HCl}$ & $\begin{array}{l}\text { Capsule, tablet, } \\
\text { floating systems }\end{array}$ \\
\hline Vertical diffusion cell & $\begin{array}{l}\text { Phosphate buffer of pH 7.4, 6.8, 5.4 } \\
\text { Water + acetone }\end{array}$ & $\begin{array}{l}\text { Hydrogel } \\
\text { Lotion, creams }\end{array}$ \\
\hline Modified Rossett-Rice cell & Phosphate buffer 7.4+ Tween 80 & Floating systems \\
\hline
\end{tabular}


Thermal analysis: Thermal behaviour can be analyzed by conducting differential scanning calorimetry (DSC) and thermo gravimetric analysis (TGA). Accurately weighed samples are placed in sealed aluminium crucibles and heated within particular temperature range and DSC thermographs of unloaded and drug loaded microsponges are recorded. 49

Pore structure determination: Pore diameter, pore volume are important parameters that controls duration of release, movement of API from microsponges. Mercury intrusion porosimetry is used to characterize porosity parameters like pore diameter, size distribution, total pore SA, percent porosity, interstitial void volume, structure and morphology of pores, bulk and true density.

Stability studies: As per ICH guidelines, stability of microsponge loaded formulation is performed at different storage and temperature conditions. For predetermined time, formulation is subjected to $40^{\circ} \mathrm{C} / 75 \% \mathrm{RH}, 25^{\circ} \mathrm{C} / 60 \%$ $\mathrm{RH}, 30^{\circ} \mathrm{C} / 65 \% \mathrm{RH}$ and $2-8^{\circ} \mathrm{C}$. Then, samples are collected at specific time intervals for physical evaluation.

Compatibility study: Drug-excipient compatibilities are determined by using methods like Thin Layer Chromatography, Fourier Transform Infrared Spectroscopy. Polymerization effect on crystallinity is analyzed by using Powder X-ray diffraction technique. ${ }^{51}$

Polymer-Monomer composition: Partition coefficient between vehicle and microsponge system and thus release rate of entrapped drug is affected by composition of polymer. A plot of cumulative \% drug release Vs time gives idea about release of entrapped drug of various polymer compositions. Characteristics of drug and vehicle determines monomer selection. ${ }^{52}$

Resiliency determination: Resiliency i.e. viscoelastic characteristics are modified to fabricate soft or rigid beadlets according to end formulation. More cross linking causes retardation of release rate. Resiliency is studied and optimized in accordance to release rate as function of cross linking with time. 53

\section{APPLICATIONS OF MICROSPONGES:}

Microsponge delivery system enhances safety, efficacy, and aesthetic quality of topical, oral, ophthalmic, over the counter as well as personal care products. This drug delivery system has variety of applications and described in table 2 .

\section{1) In topical drug delivery:}

Various drug loaded microsponges are incorporated into topical dosage forms such as emulgel, cream, powder. It improves drug residence time in epidermis and dermis reducing frequency of application. Also, side effects are reduced by using biocompatible, inert, non-toxic polymers. In topical drug delivery, microsponges have applications in: hyper pigmentation disorder (Glabridin microsponges), as anti-viral (Acyclovir microsponges), in tineapedis (Sertaconazole nitrate microsponges), as anti-fungal (Fluconazole microsponges), in rheumatoid arthritis (Mefenamic acid microsponges), as anti-acne (Benzoyl peroxide microsponges), in diabetic wound healing (Nebivolol microsponges), in psoriasis (Clobetasol propionate microsponges). 54

\section{2) In oral drug delivery:}

Though Oral route is easy to access, safe, non-toxic, it possess disadvantage of rapid excretion of drug due to short half life, extensive first pass metabolism of some formulations. So, for controlled and targeted oral delivery various microsponges formulations are prepared and having number of applications. Microsponge system improves solubilization rate of hydrophobic drugs by entrapping it into pores. Smaller microscopic particles have higher surface area that increases the solubilization rate.

By altering intra particle density of Eudragit RS, ibuprofen microsponges were prepared for controlled drug delivery. By using dry impact blending method, powder coated microsponges of chlorpheniramine maleate are prepared for sustained release. For controlled oral delivery, microsponges of Ketoprofen are prepared and then formulated as tablet by direct compression method. 55

\section{3) In bone and tissue engineering:}

When powders of polymethyl methacrylate and liquid methyl methacrylate monomer mixed with two aqueous dispersions of tricalcium phosphate grains and hydroxyapatite powder, compound obtained was porous that acts as microsponge. In a collagen sponge sheet, Basic fibroblast growth factor (bFGF) was added that has prolonged release within the mouse sub-cutis as per the biodegradation of the matrix that showed confined angiogenic effect in a dose-dependent manner. It showed increased blood flow within the murine ischaemic hind limb that suggests the significant therapeutic use of the type I collagen as a reservoir of bFGF. 56

Table 2: Applications of microsponge system

\begin{tabular}{|c|c|c|}
\hline No. & Applications & Advantages \\
\hline 1. & $\begin{array}{l}\text { Anti-acne } \\
\text { e.g. Benzoyl peroxide gel/lotion. }\end{array}$ & Maintained efficacy with minimal skin irritancy and sensitivity. \\
\hline 2. & Anti-fungal & Prolonged release of active drug. \\
\hline 3. & $\begin{array}{l}\text { Anti-inflammatory } \\
\text { e.g. Hydrocortisone }\end{array}$ & Long term effect with reduced skin allergy. \\
\hline 4. & $\begin{array}{l}\text { Sunscreens } \\
\text { e.g. Oxybenzone gel }\end{array}$ & $\begin{array}{l}\text { Long term product efficacy with enhanced skin safety against sunburns, sun } \\
\text { related injuries even at high concentration. }\end{array}$ \\
\hline 5. & $\begin{array}{l}\text { Anti-dandruff } \\
\text { e.g. selenium sulphide. }\end{array}$ & $\begin{array}{l}\text { Extended safety as well as efficiency, reduced objectionable odour and } \\
\text { minimum irritation. }\end{array}$ \\
\hline 6. & $\begin{array}{l}\text { Skin de-pigmenting agents } \\
\text { e.g. hydroquinone }\end{array}$ & Better stability against oxidation, excellent aesthetic appeal. \\
\hline
\end{tabular}




\section{RECENT ADVANCES IN MICROSPONGE DRUG DELIVERY SYSTEM:}

Some researchers, pharmaceutical companies are developing advanced formulations. They are as follows and having more stability than microsponges.

\section{1) Nanosponges:}

This are observed to be good carrier for delivery of gases. When cytotoxic is incorporated in nanosponges carrier system, it increases potency of drug so it is used for targeting cancer cells. $\beta$-CD nanosponges are developed by cross linking $\beta$-CD molecule with biphenyl carbonate. They can be used for hydrophilic as well as hydrophobic drugs. This advanced system were studied for flurbiprofen, dexamethasone, itraconazole, etc. 57

\section{2) Nanoferrosponges:}

Nanoferrosponges consists of self-promising carriers having improved penetration towards targeted area because of external magnetic response that enables carriers to go through deeper tissue and then there is exclusion of magnetic material leaving behind porous system.

\section{3) Porous microbeads:}

Porous microbeads were developed due to improved characteristics of microspheres. For developing solid porous microbeads, polymerization and cross linking technologies are used. High internal phase emulsion method uses monomer that contains external oil phase, internal aqueous phase and cross linker. The microbeads are utilized in topical, oral and buccal drug delivery system. This approach gives new therapeutic route for siRNA delivery due to superior RNA stability and efficient siRNA encapsulation. ${ }^{58}$

\section{MARKETED FORMULATIONS:}

Number of microsponge formulations is available in market for treatment of various disease conditions. Some of that are given in table 3 .

Table 3: Some marketed formulations of microsponges.

\begin{tabular}{|l|l|l|l|}
\hline Name of product & Content & Uses & Manufacturer \\
\hline Carac cream & $0.5 \%$ fluorouracil & In Actinic keratosis & Dermik Laboratories, Inc. \\
\hline EpiQuin Micro & $\begin{array}{l}\text { Hydroquinone and } \\
\text { retinol }\end{array}$ & In Hyper pigmentation & Skin Medica Inc. \\
\hline $\begin{array}{l}\text { Lactrex TM } 12 \% \text { moisturizing } \\
\text { cream }\end{array}$ & $12 \%$ lactic acid & As moisturizer & SDR Pharmaceuticals, Inc. \\
\hline Retin A Micro & $\begin{array}{l}0.1 \% \text { and } 0.04 \% \\
\text { Tretinoin }\end{array}$ & In acne vulgaris & $\begin{array}{l}\text { Ortho-McNeil } \\
\text { Pharmaceutical, Inc. }\end{array}$ \\
\hline Neobenz Micro & Benzoyl peroxide & As Anti- bacterial & Intendis Inc. \\
\hline Salicylic peel 20 & $20 \%$ Salicylic acid & $\begin{array}{l}\text { Improve fine lines, superior } \\
\text { exfoliation. }\end{array}$ & Biophora \\
\hline $\begin{array}{l}\text { Line Eliminator Dual Retinol } \\
\text { Facial Treatment }\end{array}$ & Vitamin A & Anti- wrinkle cream & Avon \\
\hline
\end{tabular}

\section{PATENT INFORMATION OF MICROSPONGES:}

1) In 1987, Won R. received patent. 59

2) In 1989, Dean RC Jr et al. received patent. 60

3) In 1992, Won R. received patent.61

4) In 1998, Froix et al. received patent. 62

5) In 1998, Lo Ray JR received patent. 63

6) In 2002, Straub et al. received patent. 64

7) In 2005, Wright et al. received patent. 65

\section{FUTURE ASPECTS:}

In upcoming years, Microsponge system will have promising future due to various pharmaceutical applications and unique, potential characteristics of porous system. One of the challenges of this system in future is oral peptide delivery which may be completed by developing core/shell delivery of drug loaded microsponges by changing and applying various polymers ratios. MDS is very emerging field that should be explored.

\section{CONCLUSION:}

Novel microsponge porous system offers various advantages over conventional formulations and has number of applications in topical, oral, ophthalmic delivery of drugs. It serves as a unique and effective technology for controlled as well as sustained release of therapeutic agents. Formulations with enhanced efficacy, safety, stability, ingredient compatibility are obtained with reduced side effects. Initially, this system was developed for topical drug delivery such as anti-acne, anti-inflammatory, anti-fungals, antipruritics, etc; but now a days, is also used for tissue engineering, colon specific drug delivery. Microsponge based drug delivery is valuable, potential drug delivery system.

\section{REFERENCES:}

1. Patel D, Gohil D, Patel D, Sheth H, Patel S, Pandya K, Shah C, Formulation and evaluation of floating microsponges of allopurinol, Pharma Science monitor, 2016; 7(3):135-154.

2. Jyoti, Kumar S, Innovative and novel strategy: Microsponges for topical drug delivery, Journal of Drug Delivery and Therapeutics, 2018; 8(5):28-34.

3. Irukonda R, Umasankar K, Reddy JP, Development and evaluation of microsponge drug delivery system of indomethacin, International Journal of Pharmacy, 2017; $7(3): 125-131$ 
4. Mohanty D, Bakshi V, Rashaid MA, Reddy TV, Dholakia NA, Madhu Babu A, Design and In- vitro characterization of betamethasone microsponge loaded topical gel, International Journal of Pharma Research and Health Sciences, 2016; 4(2):1124-1129.

5. Shaha V, Jain H, Krishna J, Patel P, Microsponge drug delivery: A review, International Journal of Research in Pharmaceutical Sciences, 2010; 1(2): 212-218.

6. Bhatt P, Patel D, Patel A, Patel A, Nagarsheth A. Oral Controlled Release Systems: Current Strategies and Challenges. In: Misra A, Shahiwala A, editors. Novel Drug Delivery Technologies: Innovative Strategies for Drug Repositioning. Singapore: Springer Singapore; 2019. p. 73-120.

7. Tile MK, Pawar AY, Microsponges: a novel strategy for drug delivery, International Journal of Pure and Applied Bioscience, 2015; 3(1):224-235.

8. Shah CN, Shah DP, Microsponges: a revolutionary path breaking modified drug delivery of topical drugs, International Journal of Pharmaceutical Research, 2014; 6(2):01-13.

9. Pathan HK, Saraf A, Dasani A. Microsponge drug delivery system as an innovation in cosmetic world: a review, Asian Journal of Pharmaceutical Education and Research, 2012; 1(2):67- 87.

10. Joshi G, Kaur R, Kaur H, Microsponges: a novel drug delivery system, International Research Journal of Pharmaceutical and Biosciences, 2016; 3(1):01-11.

11. Balamurugan K, Kshirsagar N, Govardhan P, Microsponges: as a drug delivery system, Pharma Innovation Journal, 2019; 8(1):139-143.

12. Embil K, Nacht S. The microsponge drug delivery system (MDS): a topical delivery system with reduced irritancy incorporating multiple mechanisms for the release of actives, Journal of Microencapsulation, 1996; 13(5):575-588.

13. Kumar S, Tyagi LK, Singh D, Microsponge delivery system (MDS): a unique technology for delivery of active ingredients, International Journal of Pharmaceutical Sciences and Research, 2011; 2(12):3069-3080.

14. Tiwari A, Mishra MK, Shukla A, Yadav SK, Microsponge: an augmented drug delivery system, American Journal of PharmTech Research, 2016; 6(6):80-95.

15. Kapoor D, Vyas R, Lad C, Patel M, Tyagi B, A review on microsponge drug delivery system, Journal of Drug Delivery and Therapeutics, 2014; 4(5):29-35.

16. Charde MS, Ghanawat PB, Welankiwar AS, Kumar J, Chakole RD, Microsponge a novel new drug delivery system: a review, International Journal of Advances in Pharmaceutics, 2013; 2(6):63-70.

17. Mishra SK, Kumari P, A comprehensive review on novel microsponge drug delivery approach, Asian Journal of Pharmaceutical and Clinical Research, 2016; 9(1):25-30.

18. Gandhi KJ, Deshmane SV, Biyani KR, Polymers in pharmaceutical drug delivery system: a review, International Journal of Pharmaceutical Sciences Review and Research, 2012; 14(2):57-66.

19. Taghi HS, Abdulbaqi MR, Jabar EG, Enhancement solubilization of dutasteride using microsponge formulation, International Journal of Drug Delivery and Technology, 2020; 10(1):60-67.

20. Kshirsagar N, puchchakayala G, Balamurugan K, Formulation and characterization of flurbiprofen loaded microsponge based gel for sustained drug delivery, International Journal of Research in Pharmaceutical sciences, 2019; 10(4):2765-2776.

21. Elfaham $\mathrm{TH}$, Obiedallah $\mathrm{MM}$, Abdel-Mageed AM, Ocular administration of acetazolamide microsponges In-situ gel formulations. Saudi Pharmaceutical Journal, 2018; 26(7):909920 .

22. Othman MH, Zayed GM, El-sokkary GH, Ali UF, Abdellatif AAH, Preparation and evaluation of 5-fluorouracil loaded microsponges for treatment of colon cancer, Journal of Cancer Science and Therapy, 2017; 9(1):307-313.

23. Desavathu M, Pathuri R, Chunduru M, Design, development and characterization of valsartan microsponges by quasi emulsion technique and the impact of stirring rate on microsponge formation, Journal of Applied Pharmaceutical Science, 2017; 7(1):193-198.

24. Charagonda S, Puligilla RD, Ananthula MB, Bakshi V, Formulation and evaluation of famotidine floating microsponges, International Research Journal of Pharmacy, 2016; 7(4):62-67.

25. Pawar AP, Gholap AP, Kuchekar AB, Bothiraja C, Mali AJ, Formulation and evaluation of optimized oxybenzone microsponge gel for topical delivery, Journal of Drug Delivery, 2015; 1-9.

26. Bhimavarapu R, Chitra KP, Karunkiran P, Raviteja G, Meharagavendra Y, Sundaramma S, Chaitanya D, Itraconazole loaded microsponges- a novel carrier system, International Journal of Inventions in Pharmaceutical Sciences, 2015; 3(1):953-957.

27. Osmani RA, Aloorkar NH, Kulkarni AS, Harkare BR, Bhosale $\mathrm{RR}$, A new cornucopia in topical drug delivery: microsponge technology, Asian Journal of Pharmaceutical Science and Technology, 2014; 4(1):48-60.

28. Ravi R, Senthilkumar SK, Parthiban S, Microsponges drug delivery system: a review, International Journal of Pharmacy Review and Research, 2013; 3(1):6-11.

29. Patil SS, Dandekar V, Kale A, Barhate SD, Microsponge drug delivery system: an overview, European Journal of Pharmaceutical and Medical Research, 2016; 3(8):212-221.

30. Pawar V, Salunkhe A, A review on microsponges drug delivery system, International Journal of Research and Analytical Reviews, 2020; 7(1):961-974.

31. Deore MB, Salunkhe KS, Pawbake G, Chaudhari SR, Gaikwad $\mathrm{PR}$, Microsponges as a modified drug delivery system, World Journal of Pharmaceutical Research, 2015; 4(3):657-667.

32. Shrivastava R, Pathak K, Microsponges: a futuristic approach for oral drug delivery, Expert Opinion Drug Delivery, 2012; 9(7): 863-878.

33. Han DK, Park K, Bae SE, Son JS, Fabrication of covered porous PLGA microsphere using hydrogen peroxide for controlled drug delivery and regenerative medicine, Journal of Controlled release, 2009; 133:37-43.

34. Rizkalla CZ, Aziz RL, Soliman II. In vitro and In vivo evaluation of hydroxyzine hydrochloride microsponges for topical delivery. AAPS Pharmaceutical Sciences and Technology, 2011; 12(3):989-1001.

35. Sharma S, Sharma A, Kaur C, Microsponges: as a topical drug delivery system, International Journal of Pharmaceutical Sciences and Research, 2020; 11(2):524-534.

36. Alemrayat B, Elrayees MA, Alany RG, Elhissi A, Younes HM, Preparation and optimization of monodisperse polymeric microparticles using modified vibrating orifice aerosol generator for controlled delivery of letrozole in breast cancer therapy, Drug development and industrial pharmacy, 2018; 44(12):1953-1965.

37. Shende P, Pawar S, Trotta F, Diversity of $\beta$ - cyclodextrin based nanosponges for transformation of actives, International Journal of Pharmaceutics, 2019; 565:333-350.

38. Pancholi $K$, Ahras $N$, Stride $E$, Edirisinghe $M$, Nove electrohydrodynamic preparation of porous chitosan particles for drug delivery, Journal of Material Science: Mater Med, 2009; 20:917-923.

39. Thakur R, Kumar S, Gaba P, A review: novel method for microsponge drug delivery system, Journal of Pharmacy and Biological Sciences, 2020; 15(4):35-44.

40. Upadhye SS, Kothali BK, Apte AK, Patil AA, Dandole AB, A review on microsponge drug delivery system, International Journal of Pharmaceutical Research and Bioscience, 2016; 5(1):152-166.

41. Kar AK, Kar B, Parya H, Kundu S, Hirawat R, A novel approach on microsponge: multifunctional dosage form, International Journal of Pharmaceutical Sciences Review and Research, 2018; 51(2):64-72.

42. Umamaheshwari $\mathrm{R}$, Kothai $\mathrm{S}$, An overview of microsponge as drug delivery system, $4^{\text {th }}$ International web conference on emerging trends in arts, science, engineering and technology, organized by DK International Research Foundation, ISBN number: 978-81-945642-3-2, 2020; 54-57.

43. Bhanse ND, Shah CN, Shah DP, Novel and innovative strategy: microsponges drug delivery, Pharma Science Monitor An international journal of pharmaceutical sciences, 2016; $7(2): 54-72$.

44. Ahire PV, Darekar AB, Saudagar RB, Review on microsponges as a novel drug delivery system, International Journal of Current Pharmaceutical Review and Research, 2017; 8(3):293-297. 
45. Mahajan AG, Jagtap LS, Chaudhari AL, Swami SP, Mali PR, Formulation and evaluation of microsponge drug delivery system using indomethacin, International Research Journal of Pharmacy, 2011; 2(10):64-69.

46. Junqueira MV, Calcado SC, De castro LV, Baesso ML, Jankowsa AS, Velty RA, Bruschi ML, Influence of the ethanol/dichloromethane ratio on the preparation of microsponges composed of ethylcellulose and Eudragit or HPMC phthalate for hydrophilic drug delivery, Journal of Molecular Liquids, 2020; 1-38.

47. Parikh BN, Gothi GD, Patel TD, Chavda HV, Patel CN, Microsponge as novel topical drug delivery system, Journal of Global Pharma Technology, 2010; 2(1):17-29.

48. Patel EK, Oswal RJ, Nanosponge and Microsponges: a novel drug delivery system, International Journal of Research in Pharmacy and chemistry, 2012; 2(2):237-244.

49. Shahzad Y, Saeeda S, Ghori MU, Mahmood T, Yousaf AM, Jamshaida M, Sheikh R, Syed RA, Influence of polymer ratio and surfactants on controlled drug release from cellulosic microsponges, International Journal of Biological Macromolecules, 2018; 109:963-970.

50. Shukla A, Garg A, Garg S, Application of microsponge technique in topical drug delivery system, Asian Journal of Biomaterial Research, 2016; 2(4):120-126.

51. Singhvi G, Manchanda P, Hans N, Dubey S, Gupta G, Microsponge: an emerging drug delivery strategy, Drug Development and Research, 2018; 79:1-9.

52. Jadhav N, Patel V, Mungekar S, Bhamare G, Karpe M, Kadams $\mathrm{V}$, Microsponge delivery system: an updated review, current status and future prospects, Journal of Scientific and Innovative Research, 2013; 2(6):1097-1110.

53. Ingale DJ, Aloorkar NH, Kulkarni AS, Patil RA, Microsponges as innovative drug delivery systems, International Journal of Pharmaceutical Sciences and Nanotechnology, 2012; 5(1):1597-1606.

54. Sansare V, Microsponges: a novel drug delivery system. Paripex- Indian Journal of Research, 2019; 8(9):102-104.
55. Kaity S, Maiti S, Ghosh AK, Pal D, Ghosh A, Banerjee A, Microsponges: a novel strategy for drug delivery system, Journal of Advanced Pharmaceutical Technology and Research, 2010; 1(3):283-290.

56. Shankar M, Lalitha SK, Likhitha D, Dastagiri J, Niranjanbabu M A current view on microsponge drug delivery system. European Journal of Molecular Biology and Biochemistry, 2016; 3(1):33-38.

57. Garud ST, Tiwari K, Microsponges: a novel approach, Asian Journal of Pharmaceutical Science and Technology, 2018; 8(1):1-9.

58. Valluru R, Ravi G, Bose SP, Damineni S, Microsponges- a comprehensive review: success and challenges. Indo American Journal of Pharmaceutical Research, 2019; 9(7):3056-67.

59. Won $\mathrm{R}$,Method for delivering an active ingredient by controlled time release utilizing a novel delivery vehicle which can be prepared by a process utilizing active ingredient as a porogen, 1987; United States Patent 4690825.

60. Dean Jr. RC, Silver FH, Berg RA, Phillips PG, Runstadler PW, Mafia GJ, Weighted collagen microsponge for immobilizing bioactive materials, 1989; United States Patent 4863856.

61. Won R, Two step method for preparation of controlled release formulations, 1992; United States Patent 5145675.

62. Froix M, Pukshansky M, Nacht S, Retinoid formulations in porous microspheres for reduced irritation and enhanced stability, 1998; United States Patent 5851538.

63. Lo ray JR, Microsphere reservoirs for controlled release application, 1998; United States patent 5725869.

64. Straub J, Bernstein H, Chickering DE, Khattak S, Randall G, Stoneham, Porous drug matrices and methods of manufacture thereof, 2002; United states Patent 6395300.

65. Wright SG, Christensen T, Yeoh TY, Rickey ME, Hotz JM, Kumar R, Costantino HR, Polymer based sustained release device, 2005; United States Patent 2005/ 0271702A1.

66. Rao R, Mahant S, Kumar S, Nanda S, Microsponges for dermatological applications: Perspectives and challenges, Asian Journal of Pharmaceutical sciences, 2020; 15:23-291. 